\title{
Endoscopic endonasal surgery outcomes for pediatric craniopharyngioma: a systematic review
}

\author{
Sauson Soldozy, BA, Michelle Yeghyayan, BS, Kaan Yağmurlu, MD, Pedro Norat, MD, \\ Davis G. Taylor, MD, M. Yashar S. Kalani, MD, PhD, John A. Jane Jr., MD, and Hasan R. Syed, MD \\ Department of Neurological Surgery, University of Virginia Health System, Charlottesville, Virginia
}

OBJECTIVE The goal of this study was to systematically review the outcomes of endoscopic endonasal surgery (EES) for pediatric craniopharyngiomas so as to assess its safety and efficacy.

METHODS A systematic literature review was performed using the PubMed and MEDLINE databases for studies published between 1986 and 2019. All studies assessing outcomes following EES for pediatric craniopharyngiomas were included.

RESULTS Of the total 48 articles identified in the original literature search, 13 studies were ultimately selected. This includes comparative studies with other surgical approaches, retrospective cohort studies, and case series.

CONCLUSIONS EES for pediatric craniopharyngiomas is a safe and efficacious alternative to other surgical approaches. Achieving gross-total resection with minimal complications is feasible with EES and is comparable, if not superior in some cases, to traditional means of resection. Ideally, a randomized controlled trial might be implemented in the future to further elucidate the effectiveness of EES for resection of craniopharyngiomas.

https://thejns.org/doi/abs/10.3171/2019.10.FOCUS19728

KEYWORDS endoscopic surgery; craniopharyngioma; pediatric neurosurgery; endonasal approach

$\mathrm{C}$ RANIOPHARYNGIOMAS are embryonic malformations of the sellar region with both cystic and calcified components. ${ }^{14}$ A difficult lesion to treat, the choice between using endoscopy or traditional microsurgery remains a matter of debate. On the one hand, endoscopic surgery provides better visualization of anatomical landmarks and neurovascular structures, with multiangled and close-up views being enabled by the endoscope. Despite this, views are bidimensional and limited to computerprocessed screens when compared to the superior 3D images conveyed by the surgical microscope, although the presence of a sphenoid retractor can reduce visualization. ${ }^{4}$ In the pediatric population, a conchal sphenoid sinus and smaller skull base can make an endoscopic approach more challenging. ${ }^{3}$ Regardless, the allure of endoscopic endonasal surgery (EES) lies in its ability to reach deep-seated anterior midline structures while causing minimal disruption to eloquent tissues.

Currently, EES is widely used for pituitary adenomas, Rathke cleft cysts, craniopharyngiomas, and other sellar lesions, with a significant decline in microscopic procedures in favor of EES for pituitary tumors being evident over the last 2 decades..$^{17}$ Despite this, it remains unclear whether endoscopic approaches provide outcomes that are comparable or superior to those of traditional microsurgery, with studies providing conflicting results. ${ }^{17}$ With most studies being limited to pituitary adenomas, evidence is especially lacking in the realm of craniopharyngiomas, and even fewer studies of pediatric cohorts exist. The aim of this systematic review was to identify and review studies presenting the safety and outcomes of EES for pediatric craniopharyngioma.

\section{Methods}

A literature search using PubMed and MEDLINE databases was performed with the search terms "endoscopic surgery pediatric craniopharyngioma" yielding 48 articles. After reviewing the titles and abstracts for relevance, 29 articles were selected for full-text review. Ultimately,

ABBREVIATIONS BMI = body mass index; $\mathrm{DI}$ = diabetes insipidus; $\mathrm{EES}$ = endoscopic endonasal surgery; $\mathrm{GTR}$ = gross-total resection.

SUBMITTED September 1, 2019. ACCEPTED October 16, 2019.

INCLUDE WHEN CITING DOI: 10.3171/2019.10.FOCUS19728. 


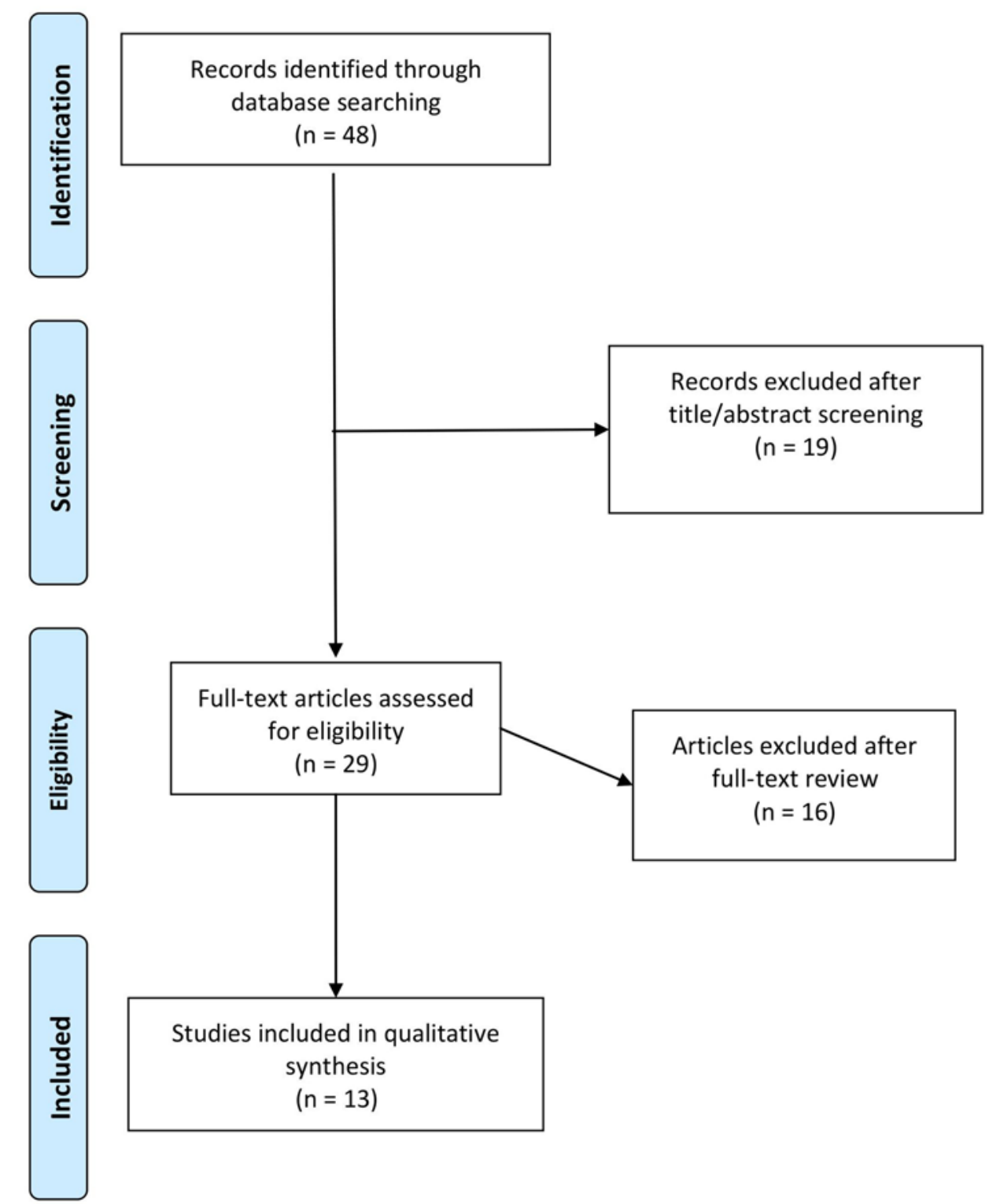

FIG. 1. Flow diagram showing the process of study selection.

13 studies were included. Case reports with fewer than 5 patients, review articles, and editorials without original data were excluded. A PRISMA flow diagram detailing methods for selection of studies is presented in Fig. 1. Data from the included studies were independently reviewed and extracted by the first and second authors.

\section{Results}

A summary of the included studies can be found in Table 1 . A total of 13 studies were included and are discussed below.

Kuan et al. ${ }^{11}$ reported the impact of sphenoid pneumatization in a retrospective cohort study that included 27 patients. The median age of the patients was 8 years, and $19(70 \%)$ were male. The authors found that the sphenoid pneumatization pattern (conchal, presellar, sellar/postsel- lar) did not impact the extent of resection (gross versus total, $\mathrm{p}=0.414$ ). Postoperative CSF leaks occurred in 2 patients $(7 \%)$, with bivariate analysis showing no association between a CSF leak and pneumatization patterns $(\mathrm{p}=$ 0.450 ). Intraoperative estimated blood loss, total operative time, and length of stay were also unaffected $(\mathrm{p}=0.098$, 0.540 , and 0.336 , respectively). While a poorly pneumatized sphenoid sinus may hinder visualization of landmarks such as the sellar bulge and opticocarotid recess, cautious dissection, intraoperative image guidance, and use of Doppler probing helps to circumvent this obstacle and limit perioperative differences despite variable sinus development in the pediatric population.

As changes in normal cranial base development may be secondary in EES, Parasher et al..$^{15}$ compared differences in midfacial growth over a period of 3 years in a retrospec- 
TABLE 1. Summary of features and findings of studies in which EES was used to treat craniopharyngiomas

\begin{tabular}{|c|c|c|c|c|c|c|c|c|}
\hline Authors \& Year & $\begin{array}{l}\text { No. of EES } \\
\text { Patients }\end{array}$ & $\begin{array}{l}\text { Study } \\
\text { Type }\end{array}$ & $\begin{array}{c}\text { FU } \\
(\mathrm{mos})^{*}\end{array}$ & $\begin{array}{l}\text { GTR } \\
(\%)\end{array}$ & $\begin{array}{c}\text { CSF } \\
\text { Leak (\%) }\end{array}$ & $\begin{array}{l}\text { New-Onset } \\
\text { Obesity (\%) }\end{array}$ & $\begin{array}{l}\text { New-Onset } \\
\text { DI (\%) }\end{array}$ & Study Conclusions \\
\hline Kuan et al., 2019 & 27 & Retro & NS & $96 \%$ & $7 \%$ & NS & NS & $\begin{array}{l}\text { Sphenoid pneumatization does not impact outcomes } \\
\text { in EES-treated pediatric craniopharyngioma } \\
\text { patients w/ respect to CSF leak, intraop blood loss, } \\
\text { total op time, \& length of stay }\end{array}$ \\
\hline $\begin{array}{l}\text { Parasher et al., } \\
2019\end{array}$ & 10 & Retro & 36 & $83.3 \%$ & NS & NS & NS & $\begin{array}{l}\text { At } 3 \text { yrs, there were no significant differences btwn } \\
\text { EES \& open transcranial approaches in pediatric } \\
\text { craniopharyngioma w/ respect to midfacial growth } \\
\text { patterns }\end{array}$ \\
\hline Chen et al., 2019 & 14 & Retro & 12 & NS & NS & NS & NS & $\begin{array}{l}\text { Postop cephalometrics are w/in normal ranges \& } \\
\text { show no significant changes btwn younger \& older } \\
\text { pediatric patients undergoing EES for craniopha- } \\
\text { ryngioma }\end{array}$ \\
\hline $\begin{array}{l}\text { Madsen et al., } \\
2019\end{array}$ & 28 & Retro & 20 & $85.7 \%$ & NS & $22.2 \%$ & NS & $\begin{array}{l}\text { EES is associated w/ similar if not superior extent of } \\
\text { resection compared to open surgery. Weight gain } \\
\text { was less prevalent in EES cohort }\end{array}$ \\
\hline $\begin{array}{l}\text { Alalade et al., } \\
2018\end{array}$ & 11 & Retro & 36 & $45 \%$ & $9 \%$ & $0 \%$ & $63.3 \%$ & $\begin{array}{l}\text { EES is suitable for pediatric craniopharyngioma even } \\
\text { in younger children w/ suprasellar tumors, conchal } \\
\text { sphenoid sinus, recurrent tumors, \& tumors w/ } \\
\text { solid components }\end{array}$ \\
\hline $\begin{array}{l}\text { Yamada et al., } \\
2018\end{array}$ & 65 & Retro & 93.6 & $91 \%$ & $9.2 \%$ & $12.2 \%$ & $84 \%$ & $\begin{array}{l}\text { GTR can be achieved w/ EES for most tumors, includ- } \\
\text { ing those w/ hypothalamic involvement, although } \\
\text { there are higher complication rates in patients } \\
\text { undergoing repeat surgery }\end{array}$ \\
\hline $\begin{array}{l}\text { Giovannetti et al., } \\
2018\end{array}$ & 12 & Retro & 22 & $75 \%$ & $16.7 \%$ & & $16.7 \%$ & $\begin{array}{l}\text { Treatment of pediatric craniopharyngiomas w/ EES is } \\
\text { feasible \& safe in this population, w/ complications } \\
\text { consistent w/ other studies }\end{array}$ \\
\hline $\begin{array}{l}\text { Stapleton et al., } \\
2017\end{array}$ & 20 & Retro & NS & NS & $17 \%$ & NS & NS & $\begin{array}{l}\text { Compared to clival chordomas \& other pituitary le- } \\
\text { sions, craniopharyngiomas had lowest CSF leak } \\
\text { rate ( } 17 \% \text { vs } 36 \% \text { \& } 25 \% \text {, respectively). There was } \\
\text { a statistically significant difference in age \& CSF } \\
\text { leak among all tumor types }\end{array}$ \\
\hline Patel et al., 2017 & 16 & Retro & 56.2 & $93.8 \%$ & $18.8 \%$ & NS & $46.7 \%$ & $\begin{array}{l}\text { Craniopharyngiomas in pediatric patients can be } \\
\text { treated w/ EES, achieving high rates of GTR \& } \\
\text { low rates of recurrence, although CSF leak \& } \\
\text { hypothalamic-pituitary dysfunction remain signifi- } \\
\text { cant postop complications }\end{array}$ \\
\hline Ali et al., 2013 & 7 & Retro & 6.3 & $100 \%$ & $14.3 \%$ & NS & $71.4 \%$ & $\begin{array}{l}\text { GTR is feasible w/ EES in pediatric patients } w / \text { cranio- } \\
\text { pharyngiomas using a binostril approach } w / \text { intraop } \\
\text { neuronavigation }\end{array}$ \\
\hline $\begin{array}{l}\text { Koutourousiou et } \\
\text { al., } 2013\end{array}$ & 17 & Retro & 38 & $52.9 \%$ & $11.8 \%$ & $33.3 \%$ & $64.7 \%$ & $\begin{array}{l}\text { EES is feasible for large suprasellar craniopharyngio- } \\
\text { mas in pediatric patients even w/ intraventricular } \\
\text { extension, w/ acceptable outcomes comparable to } \\
\text { traditional approaches }\end{array}$ \\
\hline Jane et al., 2010 & 22 & Retro & 82 & $68 \%$ & $9 \%$ & $37 \%$ & $56 \%$ & $\begin{array}{l}\text { Transsphenoidal EES approach to pediatric cranio- } \\
\text { pharyngioma lends itself to feasible GTR \& safe } \\
\text { outcomes, especially in those w/ an infradiaphrag- } \\
\text { matic origin }\end{array}$ \\
\hline $\begin{array}{l}\text { Locatelli et al., } \\
\quad 2010\end{array}$ & 5 & Retro & 103.2 & $43 \%$ & $40 \%$ & $20 \%$ & $40 \%$ & $\begin{array}{l}\text { EES is a safe \& effective approach to treating cranio- } \\
\text { pharyngioma in pediatric patients }\end{array}$ \\
\hline
\end{tabular}

FU = follow-up; NS = not stated; retro = retrospective.

${ }^{*}$ Follow-up is expressed as the mean. 
tive review of 22 patients undergoing an expanded endonasal approach $(n=12)$ or open transcranial approach $(n$ $=10$ ) to craniopharyngioma resection. While 7 of the 10 children who underwent open transcranial resection were female, only 2 of 12 who underwent the endonasal procedure were female $(p=0.027)$. Age did not vary between the groups, with a mean of 6.4 years in the open transcranial group and 7.92 years in the endonasal approach group $(p=0.297)$. At the 3 -year mark, there were no statistically significant differences in terms of growth of anterior midface height, posterior midface height, palatal length, and sella-nasion distance $(\mathrm{p}=0.880,0.839,0.894$, and 0.365 , respectively) between children who underwent the endonasal procedure and those who underwent the open transcranial procedure.

A retrospective review by Chen et al. ${ }^{5}$ also assessed the impact of endoscopic surgery on midface growth by comparing patients classified into a group receiving early intervention prior to age $7(n=11,6$ of whom had craniopharyngiomas) and a group receiving late intervention after age $7(n=37$ patients, 8 of whom had craniopharyngiomas). Their cephalometric measurements included the distance between sella (S) and nasion $(\mathrm{N})$ and the angles between the sella, nasion, the most concave point of the anterior maxilla (A), and the most concave point of the anterior mandibular symphysis (B). Postoperatively, the early-surgery group had no significant differences from standard norms for any of SNA, SNB, or ANB angles during a mean follow-up duration of 5 years $(\mathrm{p}=0.10,0.14$, and 0.67 , respectively). The $\mathrm{S}-\mathrm{N}$ distance was reduced in both the early- and late-surgery groups both pre- and postoperatively. Importantly, there was no significant difference when comparing the two age groups postoperatively in their deviation from normal growth patterns across all metrics: S-N distance, SNA, SNB, or ANB ( $\mathrm{p}=0.651$, $0.544,0.447$, and 0.305 , respectively). Similarly, there was no significant difference when comparing the two age groups in their changes from pre- to postoperative S-N distance, SNA angle, or ANB angle $(\mathrm{p}=0.87,0.89$, and 0.14 , respectively).

In a retrospective review, Madsen et al. ${ }^{13}$ explored the outcomes and complications of an $\operatorname{EES}(n=28)$ versus open surgery $(n=15)$ for craniopharyngiomas in pediatric patients with a mean age of 8.2 years. A matched cohort analysis was performed to compare the 11 patients with the largest tumors in the endoscopic group to 11 patients in the open surgery group. They found no difference in the mean postoperative tumor volumes in the unmatched $(\mathrm{p}=0.19)$ and matched $(\mathrm{p}=0.28)$ cohorts across the two approaches. The rate of recurrence, mean time to recurrence, need for adjuvant radiation, and need for additional surgery did not differ between the groups $(\mathrm{p}=0.13,0.26$, 0.71 , and 0.36 , respectively). However, the rate of grosstotal resection (GTR) was significantly higher in the EES group than the open surgery group $(\mathrm{p}=0.03)$. Additionally, there was an increased prevalence of complications in the open surgery group in both unmatched $(p=0.00001)$ and matched $(\mathrm{p}=0.004)$ analyses, with the open surgery approach having a larger median volume of ischemia postoperatively. There was a positive correlation between body mass index (BMI) and volume of diffusion-weighted im- aging signal change across the entire cohort of patients ( $p$ $=0.05$ ), excluding only the 2 patients in the open surgery groups with large cortical infarcts that were nonrepresentative of hypothalamic injury. Accordingly, there was a significantly greater mean BMI postoperatively $(\mathrm{p}=0.03)$ and greater change in BMI from before surgery to after surgery $(p=0.03)$ in the open surgery group as compared to the EES group. CSF leaks were encountered in all patients in the EES group intraoperatively, but only 2 patients had postoperative CSF leaks requiring intervention, with no incidences of meningitis. There was one death of unknown etiology in a patient with panhypopituitarism and obstructive sleep apnea in the EES group 26 months after surgery.

Alalade et al. ${ }^{1}$ published a case series of 11 pediatric patients (mean age 7.9 years) undergoing an expanded endonasal endoscopic transsphenoidal approach for craniopharyngioma. GTR was achieved in $45 \%$ of patients, with $18 \%$ of patients undergoing near-total resections and $27 \%$ undergoing subtotal resections. The $45 \%$ rate of GTR was due to either preoperative plans for subtotal resection (n $=1$ ) or intraoperative limitations of its feasibility due to tumor invasiveness and concern for hypothalamic damage. As such, $100 \%$ of patients without preoperative hypothalamic involvement underwent GTR $(n=3)$. Ultimately, $81.8 \%$ of patients developed anterior pituitary dysfunction, and $63.6 \%$ developed posterior pituitary dysfunction, with $54 \%$ of patients developing permanent diabetes insipidus (DI). Among the 10 patients with normal or near-normal hypothalamic pituitary function preoperatively, $60 \%$ experienced new-onset hypopituitarism, 50\% experienced thyroid dysfunction, and 10\% experienced growth hormone dysfunction postoperatively. Additionally, 18\% of patients experienced a $9 \%$ or greater increase in BMI postoperatively. Among the 7 patients who had impaired vision preoperatively, there was a $42.9 \%$ rate of improvement postoperatively, with $28.6 \%$ of patients experiencing no change and $28.6 \%$ experiencing worsening. Among the 4 patients with normal preoperative vision, only 1 patient experienced worsening postoperatively, with the remaining 3 maintaining normal vision. Eight of the 11 patients had no postoperative nasal symptoms such as epistaxis, hyposmia, or anosmia. One patient experienced tumor recurrence at a mean follow-up duration of 43 months, while 5 patients received postoperative radiotherapy. With regard to complications, 1 patient had a CSF leak, 1 patient required a hematoma evacuation, 1 patient developed an optic nerve infarct, and 1 patient developed an intracranial abscess.

Another case series by Yamada et al. ${ }^{19}$ examined outcomes of transsphenoidal surgery in 65 pediatric patients with craniopharyngiomas (mean age 9.6 years) treated with GTR. The patients were divided into two groups based on whether they were undergoing primary surgery $(n=45)$ or repeat surgery $(n=20)$. The overall rate of GTR across both groups was $91 \%$, with a significantly higher rate in the primary surgery group than in the repeat surgery group $(\mathrm{p}=0.009)$. The two methods used, microscopic transsphenoidal surgery $(n=46)$ and pure endoscopic transsphenoidal surgery $(n=19)$, did not have any significant difference in their rate of GTR; rather, GTR 
feasibility overall was limited by invasion of surrounding structures rather than the surgical technique itself. At a median follow-up duration of 7.8 years, $12 \%$ of patients who underwent GTR experienced tumor recurrence, without a statistically significant difference between the primary and repeat surgery groups $(p=0.06)$. With regard to the effect of intrinsic tumor qualities on outcome, the only factors that increased the rate of GTR were the small size of the tumor $(\mathrm{p}=0.008)$ and the mainly cystic composition of some tumors $(\mathrm{p}=0.03)$. Examining postoperative complications, the study found that $80 \%$ of primary surgery patients experienced pituitary dysfunction and $83 \%$ developed DI, while $100 \%$ of repeat surgery patients experienced these issues. Repeat surgery patients had both a decreased rate of visual improvement $(\mathrm{p}<0.001)$ and an increased rate of visual deterioration $(\mathrm{p}=0.04)$ compared to the patients in the primary surgery group; the overall patient cohort with preexisting visual deficits experienced improvement in $62 \%$ of cases and worsening in $11 \%$ of cases. The rate of new-onset obesity postoperatively was low in both groups $-9 \%$ among primary surgery patients and $21 \%$ among repeat surgery patients-without significant difference between the groups; however, $25 \%$ of repeat surgery patients had preoperative obesity that was secondary to a prior surgery. While there were no perioperative deaths, complications occurred in $18 \%$ of cases overall, which included CSF leakage $(n=6)$, meningitis $(\mathrm{n}=3)$, transient memory disturbance $(\mathrm{n}=2)$, and hydrocephalus $(\mathrm{n}=1)$.

A retrospective chart review by Giovannetti et al. ${ }^{8}$ examined the postoperative complications of 44 pediatric patients who underwent endoscopic endonasal skull base surgery, with the single most common indication being craniopharyngioma $(n=12)$. Overall, the mean age was 12.5 years, and the mean follow-up period was 22 months. Of the 12 craniopharyngioma patients (a sellar location in 7 and a suprasellar location in 5), GTR was achieved in 9 patients, while the 3 remaining patients underwent neartotal resection due to lesion adherence to either the internal carotid artery or optic chiasm. These 3 patients then received postoperative radiation therapy. No tumor recurrences were recorded at any follow-up time, ranging from 2 to 36 months. The postoperative complications among craniopharyngioma patients included 2 cases of CSF leak and 2 cases of DI.

In a retrospective chart review, Stapleton et al..$^{18}$ specifically addressed the risk of postoperative CSF leaks among 55 pediatric patients who underwent endoscopic endonasal skull surgery for a variety of indications. Among the patients included in the study, there were 20 patients with craniopharyngiomas, whose mean age was 8.43 years and whose mean BMI was $19 \mathrm{~kg} / \mathrm{m}^{2}$. There was no correlation between BMI and risk of CSF leak; however, across all pathologies, patients in the second and fourth quartiles of age (5.8-9.6 years and $>16.2$ years, respectively) were at a higher risk of CSF leak postoperatively, despite there being no correlation to disease pathology. Among the 55 patients in the study, 47 experienced an intraoperative CSF leak, 11 of whom subsequently developed postoperative hydrocephalus. The rate of CSF leak following EES, in craniopharyngioma patients specifically, was $17 \%$. Lum- bar drains were placed postoperatively in patients at highrisk for hydrocephalus, which occurred in 25 patients, 16 of whom were craniopharyngioma patients; all 6 patients who developed postoperative hydrocephalus were craniopharyngioma patients. However, postoperative hydrocephalus or lumbar drain placement was not correlated with the development of a CSF leak ( $\mathrm{p}=0.614$ and 1.0, respectively). The craniopharyngiomas were classified as a sellar or suprasellar pathology alongside pituitary adenoma, pituitary carcinoma, and Rathke cleft cyst for the purposes of comparison to posterior fossa pathology, which included clival chordomas; there was no significant difference in the leakage rates between these two groups ( $\mathrm{p}=$ 0.256 ). The study reported a low postoperative complication rate overall, noting that 1 craniopharyngioma patient developed a hematoma that required intervention. Repeat surgery was required for 7 craniopharyngioma patients.

Patel et al. ${ }^{16}$ published a retrospective review of 16 pediatric craniopharyngioma patients who underwent EES in an effort to examine surgical outcomes. The mean age of the patients was 11.0 years, and the median follow-up duration was 56.2 months. GTR was achieved in all but 1 case. Deficits in vision were improved or normal vision was maintained in $69.2 \%$ of cases. The rates of new panhypopituitarism, DI, and hypothalamic obesity were $63.6 \%, 46.7 \%$, and $28.6 \%$, respectively. Other complications included CSF leaks postoperatively at a rate of $18.8 \%$ and death from a postoperative intraventricular hemorrhage in 1 case. One of the patients who underwent GTR experienced tumor recurrence.

Ali et al. ${ }^{2}$ evaluated outcomes during a mean follow-up period of 6.3 months in 7 pediatric patients with craniopharyngiomas who underwent GTR in which EES was used. With a mean age of 9.6 years, no patients had undergone prior surgery or radiation therapy for a craniopharyngioma. Tumors were located in sellar and suprasellar regions, with third ventricle invasion in 6 patients. The mean hospital stay was 15 days. No visual deficits were reported in 3 patients, with another 3 noting improvement of their visual deficits and 1 patient developing delayed right Horner's syndrome. New panhypopituitarism occurred in 5 patients. New DI was reported in 5 patients, with CSF leak occurring in 1 case. These leaks occurred despite the fact that fat, fascia lata, fibrin glue, and vascularized nasoseptal flap skull base closure were used.

In a retrospective study, Koutourousiou et al. ${ }^{10}$ reviewed 64 patients (47 adults and 17 children). The mean age in the pediatric group was 9 years. Among the 17 children, 9 had exhibited ventricular extension. Utilizing EES, GTR was achieved in 9 patients, with near-total resection (> 95\% resection) in 8 patients. Of 6 pediatric patients with visual impairment on admission, 4 experienced resolution, 2 experienced improvement, and no patient experienced new visual deficits. New pituitary dysfunction occurred in 8 patients. DI either remained unchanged (3 patients) or presented as a new deficit (11 patients), and it was noted as a permanent deficit in this study. Complications included CSF leak (2 patients), hydrocephalus (2 patients), meningitis ( 2 patients), and cranial nerve palsy (3 patients). Disease recurred in 7 children, and this was not significantly different from the rate of recurrence in adults $(\mathrm{p}=0.49)$. 
Jane et al. ${ }^{9}$ retrospectively evaluated 22 patients who underwent EES as a primary $(\mathrm{n}=11)$ or a secondary $(\mathrm{n}=$ 11) procedure after a previous procedure. Prior treatments consisted of cyst aspiration, bleomycin treatment, radiosurgery, and open cranial approaches. This series selected for patients with primarily infradiaphragmatic craniopharyngiomas. GTR was achieved in 15 patients (68\%). In a mean follow-up period of 82 months, 4 patients experienced recurrence. Recurrence occurred the least (13\%) in patients who had undergone GTR when compared to all other degrees of resection (28.5\%). In addition, tumor recurrence was less likely in the primary EES group, occurring in $9 \%$ of patients as opposed to $30 \%$ of patients who received EES as a secondary measure. New panhypopituitarism occurred in $67 \%$ of patients, and new DI occurred in $56 \%$ of patients. In 14 patients with preoperative visual deficits, vision improved or normalized in 9 patients (64\%). A CSF leak occurred in 2 patients, $37 \%$ of patients experienced new-onset obesity, and 1 patient died 3 weeks postoperatively. Overall, $35 \%$ of patients in this series experienced either a major or minor complication.

Locatelli et al. ${ }^{12}$ reported a case series of 27 pediatric patients who underwent endoscopic endonasal transsphenoidal surgery for sellar tumors. Of these, 5 patients (mean age 9.2 years) had craniopharyngiomas. While sellar tumors overall were associated with a GTR rate of $81.5 \%$, craniopharyngiomas considered independently had a GTR rate of $43 \%$, with subtotal and partial resection each occurring in $29 \%$ of cases. Preoperative hypostaturalism was found in 3 patients-all of whom had craniopharyngiomas - that improved postoperatively in 2 cases and remained stable in 1 case; growth hormone was administered in all cases. Preoperative hypopituitarism in 5 craniopharyngioma patients and 1 macroadenoma patient subsequently regressed or improved in 4 cases and remained stable in 1 case, with ACTH or TSH replacement in 5 of 6 cases. Moderate obesity developed in 1 patient with craniopharyngioma. With regard to complications, postoperative CSF fistulas developed in 2 craniopharyngioma patients and 1 pituitary adenoma patient. The overall surgical morbidity rate was low, and no deaths occurred in a follow-up period that ranged from 1 to 12.4 years.

\section{Discussion}

The majority of studies found overall good outcomes when EES was conducted to treat craniopharyngiomas in the pediatric population (Table 1). In studies comparing EES to transcranial approaches, outcomes were comparable. New-onset DI, obesity, and CSF leak were among the most commonly reported outcomes and complications following EES, with age appearing to impact the risk of CSF leak in one study. ${ }^{18}$ Extended EES was performed in one study, appearing to have similar outcomes to those achieved using the standard endoscopic approach. ${ }^{1}$ Utilizing the infrachiasmatic corridor, this approach enables surgical access to craniopharyngiomas that extend into the suprasellar or intraventricular space that may posteriorly tether to the mammillary bodies or basilar artery. ${ }^{6,7}$ A technique that involves removal of the upper half of the sella turcica, the tuberculum sellae, and the posterior portion of the planum sphenoidale, the extended EES approach provides an alternative strategy to the pterional approach for these lesions. ${ }^{6}$

In pediatric patients, there is often concern for the effect of extent of sinus pneumatization on outcomes, as it is thought to make EES more difficult. While Kuan et al. ${ }^{11}$ have acknowledged that a poorly pneumatized sphenoid sinus might impair optimal visualization, no differences in resection or outcomes, such as CSF leak, were appreciated among patients with different stages of sinus pneumatization. Another factor to consider is the impact EES may have on midfacial growth in the pediatric population. Parasher et al., ${ }^{15}$ during a 3-year follow-up period, found no differences in midfacial growth between patients who underwent EES versus those who underwent transcranial microsurgery. In addition, Chen et al..$^{5}$ noted no changes in midfacial growth after EES in patients younger and older than 7 years of age. The age cutoff of 7 was chosen as the time at which cranial base development would stop affecting midfacial growth due to cranial suture fusion. These findings suggest that the operation is not associated with changes in midfacial growth and that the extent of pneumatization should be considered during preoperative planning but not considered a deterrent to EES for craniopharyngioma.

When EES is utilized as the first-line treatment for pediatric craniopharyngiomas, patients experience better outcomes and reduced recurrence rates overall compared to those for whom EES is a secondary procedure, ${ }^{, 19}$ although this is confounded by the fact that lesions requiring staged treatment or reoperation are inherently more likely to present with increased rates of complications and recurrence. Compared to microsurgery, EES was identified to be superior by Madsen et al. ${ }^{13}$ after controlling for tumor size. It should be noted that directly comparing transcranial approaches to EES is complicated by inherent selection bias such that EES is typically reserved for smaller sellar lesions, as purely suprasellar craniopharyngiomas are believed to be better treated with microsurgery. ${ }^{9,10}$

Limitations to this review include selection bias and the low number of published studies on this topic. The decision not to perform quantitative analysis was made because of the heterogeneity among the included studies with regard to patient selection and tumor morphology. Direct comparisons between and among studies is further complicated by differences in surgeon experience, as well as the inherent changes to EES techniques and practices over the last decade. In addition, while GTR is preferred, it is deferred in cases in which hypothalamic invasion is evident. For this reason, the extent of resection should not be used as a marker of the effectiveness of EES but rather evaluated in the context of a given lesion. Given the large heterogeneity of craniopharyngiomas and their presentations, it remains difficult to evaluate EES based on GTR alone.

\section{Conclusions}

The utility of EES is that it provides a minimally invasive alternative to traditional transcranial approaches. Currently, a consensus has not been reached with regard to an optimal treatment approach, with the decision to 
perform EES over traditional means remaining controversial. Despite this, recent trends have shown EES to have become increasingly implemented in transsphenoidal pituitary surgery, overtaking microsurgery as the preferred approach. Notwithstanding, it remains unclear whether EES is as safe or superior to traditional approaches in the treatment of pediatric craniopharyngiomas, with limited studies being available in the literature. In this systematic review, we presented the most recent articles describing outcomes following EES in pediatric patients with craniopharyngiomas. Outcomes seem to be dependent on tumor morphology and the extent of invasion rather than treatment approach, although direct comparisons between studies remain difficult. Despite this, transsphenoidal EES for craniopharyngiomas appears to be safe in pediatric patients, with limited impact on midfacial growth and acceptable outcomes and complication rates.

\section{References}

1. Alalade AF, Ogando-Rivas E, Boatey J, Souweidane MM, Anand VK, Greenfield JP, et al: Suprasellar and recurrent pediatric craniopharyngiomas: expanding indications for the extended endoscopic transsphenoidal approach. J Neurosurg Pediatr 21:72-80, 2018

2. Ali ZS, Lang SS, Kamat AR, Adappa ND, Palmer JN, Storm $\mathrm{PB}$, et al: Suprasellar pediatric craniopharyngioma resection via endonasal endoscopic approach. Childs Nerv Syst 29:2065-2070, 2013

3. Alli S, Isik S, Rutka JT: Microsurgical removal of craniopharyngioma: endoscopic and transcranial techniques for complication avoidance. J Neurooncol 130:299-307, 2016

4. Cavallo LM, de Divitiis O, Aydin S, Messina A, Esposito F, Iaconetta G, et al: Extended endoscopic endonasal transsphenoidal approach to the suprasellar area: anatomic considerations-part 1. Neurosurgery 62 (6 Suppl 3):1202-1212, 2008

5. Chen W, Gardner PA, Branstetter BF, Liu SD, Chang YF, Snyderman $\mathrm{CH}$, et al: Long-term impact of pediatric endoscopic endonasal skull base surgery on midface growth. J Neurosurg Pediatr 23:523-530, 2019

6. Conger AR, Lucas J, Zada G, Schwartz TH, Cohen-Gadol AA: Endoscopic extended transsphenoidal resection of craniopharyngiomas: nuances of neurosurgical technique. Neurosurg Focus 37(4):E10, 2014

7. de Divitiis E, Cappabianca P, Cavallo LM, Esposito F, de Divitiis O, Messina A: Extended endoscopic transsphenoidal approach for extrasellar craniopharyngiomas. Neurosurgery 61 (5 Suppl 2):219-228, 2007

8. Giovannetti F, Mussa F, Priore P, Scagnet M, Arcovio E, Valentini V, et al: Endoscopic endonasal skull base surgery in pediatric patients. A single center experience. J Craniomaxillofac Surg 46:2017-2021, 2018

9. Jane JA Jr, Prevedello DM, Alden TD, Laws ER Jr: The transsphenoidal resection of pediatric craniopharyngiomas: a case series. J Neurosurg Pediatr 5:49-60, 2010

10. Koutourousiou M, Gardner PA, Fernandez-Miranda JC, Tyler-Kabara EC, Wang EW, Snyderman CH: Endoscopic endonasal surgery for craniopharyngiomas: surgical outcome in 64 patients. J Neurosurg 119:1194-1207, 2013
11. Kuan EC, Kaufman AC, Lerner D, Kohanski MA, Tong CCL, Tajudeen BA, et al: Lack of sphenoid pneumatization does not affect endoscopic endonasal pediatric skull base surgery outcomes. Laryngoscope 129:832-836, 2019

12. Locatelli D, Massimi L, Rigante M, Custodi V, Paludetti G, Castelnuovo P, et al: Endoscopic endonasal transsphenoidal surgery for sellar tumors in children. Int J Pediatr Otorhinolaryngol 74:1298-1302, 2010

13. Madsen PJ, Buch VP, Douglas JE, Parasher AK, Lerner DK, Alexander E, et al: Endoscopic endonasal resection versus open surgery for pediatric craniopharyngioma: comparison of outcomes and complications. J Neurosurg Pediatr 24:236-245, 2019

14. Müller HL: Craniopharyngioma. Endocr Rev 35:513-543, 2014

15. Parasher AK, Lerner DK, Glicksman JT, Storm PB, Lee JYK, Vossough A, et al: The impact of expanded endonasal skull base surgery on midfacial growth in pediatric patients. Laryngoscope [epub ahead of print], 2019

16. Patel VS, Thamboo A, Quon J, Nayak JV, Hwang PH, Edwards M, et al: Outcomes after endoscopic endonasal resection of craniopharyngiomas in the pediatric population. World Neurosurg 108:6-14, 2017

17. Rolston JD, Han SJ, Aghi MK: Nationwide shift from microscopic to endoscopic transsphenoidal pituitary surgery. Pituitary 19:248-250, 2016

18. Stapleton AL, Tyler-Kabara EC, Gardner PA, Snyderman $\mathrm{CH}$, Wang EW: Risk factors for cerebrospinal fluid leak in pediatric patients undergoing endoscopic endonasal skull base surgery. Int J Pediatr Otorhinolaryngol 93:163-166, 2017

19. Yamada S, Fukuhara N, Yamaguchi-Okada M, Nishioka H, Takeshita A, Takeuchi Y, et al: Therapeutic outcomes of transsphenoidal surgery in pediatric patients with craniopharyngiomas: a single-center study. J Neurosurg Pediatr 21:549-562, 2018

\section{Disclosures}

The authors report no conflict of interest concerning the materials or methods used in this study or the findings specified in this paper.

\section{Author Contributions}

Conception and design: Syed, Soldozy. Acquisition of data: Soldozy, Yeghyayan. Analysis and interpretation of data: Soldozy, Yeghyayan. Drafting the article: Soldozy, Yeghyayan. Critically revising the article: Syed, Soldozy, Yeghyayan, Yağmurlu, Norat, Taylor. Reviewed submitted version of manuscript: all authors. Approved the final version of the manuscript on behalf of all authors: Syed. Administrative/technical/material support: Syed, Kalani, Jane. Study supervision: Syed.

\section{Correspondence}

Hasan R. Syed: University of Virginia Health System, Charlottesville, VA.hrs3z@virginia.edu. 